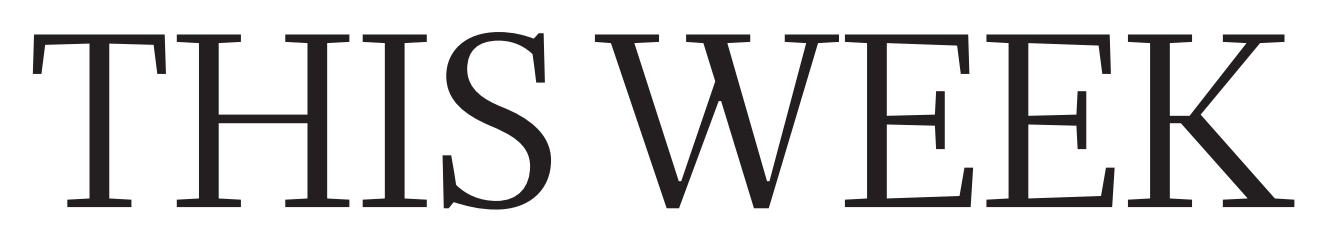

EDITORIALS

MICE Tasting menu points to environmental differences $\mathbf{p . 2 5 4}$
WORLD VIEW Push innovation science onto the agenda $\mathbf{p . 2 5 5}$
ROACH ROBOT Squashy survivors inspire flattening ately device $\mathbf{p} .257$

\title{
Green-sky thinking
}

\author{
Environmental agencies must go much further in regulating aircraft emissions if they \\ want to make a real difference.
}

A ttitudes towards flying say a lot about someone's view on global warming. A hardy bunch of committed worriers take the train instead, whereas others still celebrate the jet-set lifestyle as a sign of success. Then there are those who fly, but feel guilty about doing so.

Aviation has become a symbol of the world's reluctance to make serious efforts to tackle climate change - perhaps unfairly, given its relatively slight (although growing) contribution to the globalwarming problem. On an individual level, those who travel by air leave gigantic carbon footprints, governments continue to invest in runways and airports, and the industry remains focused on growth.

Most international frameworks to tackle carbon emissions struggle to include aviation. When the European Union tried to encompass emissions from international aviation in its emissions-trading scheme in 2012, it met with widespread protest from the industry and governments. Instead, the International Civil Aviation Organization (ICAO) - the United Nations body that oversees the skies - agreed to come up with its own measures.

The world saw the initial results of the ICAO's work last week, when the organization proposed a new global carbon dioxide standard for aircraft (see page 266). It was hardly an inspiring achievement. The proposed regulation, which is expected to be adopted later this year, is complex, but the gist is that all new aircraft would need to meet minimum fuel-efficiency standards by 2028. The ICAO says that the rule will guarantee reductions in $\mathrm{CO}_{2}$ emissions. This may be true, but it is misleading.

An independent assessment by the International Council on Clean Transportation (ICCT) suggests that new aircraft would emit on average $4 \%$ less $\mathrm{CO}_{2}$ when the measure takes full effect. However, each generation of new aircraft is already made to be more fuel efficient than the last, and the same independent assessment highlights that aircraft manufacturers are likely to achieve an efficiency improvement of more than $10 \%$ by the time the new standard kicks in, effectively rendering the rule redundant.

Still, the most notable thing about the global standard will be that it exists. It is both a precedent and a tool that could one day be used to push the industry further than it would go of its own accord.

Individual countries could yet adopt stricter regulations. Last year, the US Environmental Protection Agency (EPA) issued an 'endangerment' finding for aviation emissions, which represents the first step in a regulatory process under the country's Clean Air Act. The EPA is expected to finalize its finding in the coming months, and then it could launch its own regulatory proposal. The agency could, and should, go well beyond the ICAO standard on new aircraft, and introduce rules for existing aeroplanes.

The EPA will not be able to complete this process before President Barack Obama leaves office, so it will be up to whoever is elected president in November to follow through. Given the general opposition by US conservatives to any kind of action on climate change, there is little hope of getting a strong regulation from a Republican administration. Moreover, whatever the EPA proposes will surely be challenged in the courts, which can be fickle and unpredictable, as evidenced by the Supreme Court's decision last week to block implementation of Obama's power-plant regulations pending the outcome of a legal challenge. But one thing is clear: the EPA must act on flights, and environmentalists will surely take the agency to court if it does not. "Now is a good
time to invest in a much cleaner future."

Nor is the ICAO's work done. The body will now address a plan to halt emissions from international aviation at 2020 levels. This is crucial because international aviations already account for roughly $1.4 \%$ of global $\mathrm{CO}_{2}$ emissions and are currently unregulated. Even the global climate agreement signed in December in Paris neglected to account for emissions from aviation or from international shipping, which is responsible for nearly $1.8 \%$ of the world's $\mathrm{CO}_{2}$ emissions (see page 275).

Zero-emissions aircraft are not likely to be flying any time soon, so the key to the ICAO's idea is the use of carbon offsets. It is probable that some kind of fee would be levied on international flights to pay for emissions reductions elsewhere. But there is scope to go further on cleaner aircraft too.

Airlines are currently reaping profits thanks to the collapse of the oil market, which has lowered fuel prices across the board. Despite opposition from the aviation industry to strong emissions rules, now is a good time for it to invest in a much cleaner future..

\section{Back to Earth}

\section{Success against cancer need not deliver}

the Moon.

$\mathrm{W}$ hen John F. Kennedy pledged in a 1961 presidential speech to land a man on the Moon and return him safely to Earth, he launched more than a space programme. He introduced the ultimate metaphor. Today, moonshots no longer need to shoot for the Moon. They can signify merely the launch of a grand effort fuelled by bold ambition that will elevate society to some new heights.

The latest is the US Cancer Moonshot, a US\$1-billion plan, to be spearheaded by vice-president Joe Biden, that aims "to eliminate cancer as we know it".

The project and the promised investment are welcome indeed. The name and the rhetoric less so, and not just because they are so unoriginal - moonshots and Apollo programmes have been launched 
in recent years on everything from renewable energy and neuroscience to an assortment of Google $\mathrm{X}$ pet projects and at least three efforts to fight cancer.

Perhaps the United States was due for another national promise to cure cancer: the last - a 2005 pledge by Andrew von Eschenbach, then head of the US National Cancer Institute - was scheduled to have vanquished the disease by 2015. This followed then President Richard Nixon's 1971 pledge to use $\$ 100$ million to cure cancer. To be sure, pledges to cure cancer have a long history of succeeding in one respect: fundraising. But the idea that $\$ 1$ billion could eliminate cancer is misleading, and only becomes more so as each passing year reveals more about the full challenge of fighting the disease. With apologies to Biden, the more we 'know it' the harder it becomes to think we can 'eliminate cancer'.

Today, we have a clearer view of cancer's complexity. The sequencing of tumour genomes has revealed heterogeneity not only among cancers and patients, but in a single tumour. Within those complex mixtures of cells can lurk mutations that give rise to drug resistance. Therapies against cancer-causing mutations have been transformative for some patients in the short term, but nearly always fail in the long term as resistant cells reseed the tumour.

Real progress is being made, little by little. Chemotherapy cures more than $85 \%$ of children with acute lymphocytic leukaemia, for example. And for a small number of patients with various cancers, new immunotherapies have produced remissions so prolonged that doctors have begun to whisper the word 'cure'. But although combinations of these therapies could hold the key to expanding their success, testing combinations in clinical trials is complex - and quite likely to cost more than $\$ 1$ billion. As with everything, the more successful we get, the harder it is to improve. For many cancers, a more reasonable aim might be to turn them into chronic, manageable diseases.

In statements and conversations, Biden has acknowledged this complexity, and has even reportedly expressed regret for choosing the moonshot theme. It is unfortunate that sound bites from Biden and

the White House continue to back its simplistic framework. Repeated invocations of these bold but doomed quests to cure cancer in a decade, or with a given sum of money, feed public cynicism about the value and potential of science. And setting an unreachable goal plays down the tremendous progress that cancer researchers have made.

Details of the latest cancer moonshot are sketchy; Biden is still gathering input from the country's scientific glitterati. From what we know, he

"Setting an goal plays down

the tremendous

progress

that cancer

researchers

have made." hopes to double the pace of cancer research by breaking down the barriers - logistical and cultural - that keep researchers from sharing data. This can include having electronic medical records that talk to one another, encouraging collaboration, and developing central repositories that can handle big data. Some of these issues are already being tackled: the National Cancer Institute, for example, is putting together a large database that aims to unite disparate data sets, along with clinical information and the privacy concerns entailed, in one place.

There is also no guarantee that Obama's $\$ 1$-billion request will come to pass. Congressional leaders have pledged to ignore the president's budget request. And Obama sought to establish the funding for the cancer moonshot using an unusual approach that would circumvent the usual congressional funding process. Congress is unlikely to sign up to that. But there is hope that the programme will survive in some form: this Congress has a soft spot for medical research, and Biden is an authority on the art of congressional compromise.

Let us hope it will. Biden's early vision of the programme, if executed well, has the potential to be high-impact. Cancer research is in the middle of a revolution, and may be on the brink of even greater success. The US Cancer Moonshot has the potential to build on this momentum. The project does not need to mislead the public, and damage its trust in science, in the process.

\section{Chow down}

\section{Scientists should pay more heed to the varying effects of diet and environment on animal work.}

$\mathrm{J}$ apanese scientists last year reported the results of an extraordinary experiment in animal nutrition. The mice they worked with could well have been the best fed in the history of research - not in terms of quantity of food, but in its quality.

On a typical day, one group of mice got to eat mixed rice with dried whitebait and green seaweed flakes for breakfast, together with cooked beans and miso soup containing the root vegetable taro and Japanese mustard spinach. Another group got bacon and eggs, toast and fluffy boiled potatoes. Lunch for one group could be simmered pumpkin and ground chicken, with a portion of cucumber and wakame seaweed with vinegar dressing. A different group of mice got a hamburger and salad.

Dinner was selected by the scientists from dishes including prawns with chilli sauce, Sichuan-style bean curd, fried Japanese horse mackerel, white radish and shimeji mushroom soup, sake-steamed clams and steamed Japanese seerfish. The mice ate from that kind of menu every week of their lives. There was no pudding, but probably no complaints.

The reason for all this gourmet cuisine was to recreate the typical Japanese diet from decades past, and to examine its impact on health. The long life expectancy of people in Japan has been attributed to the benefits of Nihon shoku or traditional diet, involving fermented foods that seem to boost the protective effect of harmless microbes on and in the body. As the food available in Japan has become increasingly Westernized, the effects on health are being questioned.
Hence the mouse study. Each group was given dishes from recreated daily menus for a typical Japanese household in 1960, 1975, 1990 and 2005. The food was ground up and fed to the animals along with their regular meals of 'standard laboratory chow'. As the scientists suspected, the animals that were fed the older, more traditional diets lived and prospered for longest (K. Yamamoto et al. Nutrition 32, 122-128; 2016).

There are two things to note. The first is the large contribution that the environment - in this case diet - can make to health. The second is that such experiments enable the impact of environment on health to be assessed in ways that are simply not possible for human trials.

Light, heat, food, company, exercise, distractions, stress - all are at the fingertips of scientists who set up mouse experiments. Subtle changes in any of these can lead to profound, and potentially useful, discoveries about how health is changed by external factors. Research has probed, for example, how giving mice tunnels, stairs and wheels to play with can alter how female mice interact with their young, which in turn alters the brain development of the offspring (T. Begenisic et al Neurobiol. Dis. 82, 409-419; 2015). There is some evidence that modern, sterile, individually ventilated cages - used to minimize the effects of environmental factors such as disease - are quieter and less smelly for the mice, which reduces stimulation of those sensory systems.

Given that we know that environment affects the outcome of experiments, it is surprising that we don't know more about the environmental set-up of other studies - those that test the impact of a potential medical treatment, for example. As we report in a News story on page 264, many researchers who use mice do not even know
D NATURE.COM To comment online, click on Editorials at: go.nature.com/xhunqv the content of standard lab chow and how it may change from study to study. As scientists hunt for sources of irreproducibility in their research, variation in living conditions - and how to reduce it - deserves more attention. 